OPEN ACCESS

Edited by:

Haojie Lu,

Fudan University, China

Reviewed by:

Enzo Spisni,

Università degli Studi di Bologna, Italy Markus Niessen,

Universität Zürich, Switzerland

${ }^{*}$ Correspondence:

Feng Guan

fengguan@jiangnan.edu.cn;

guanfeng@nwu.edu.cn

Specialty section:

This article was submitted to

Clinical and Translational Physiology,

a section of the journal

Frontiers in Physiology

Received: 07 September 2017

Accepted: 13 April 2018

Published: 03 May 2018

Citation:

Zhuo D, Li X and Guan F (2018) Biological Roles of Aberrantly

Expressed Glycosphingolipids

and Related Enzymes in Human

Cancer Development and Progression.

Front. Physiol. 9:466.

doi: 10.3389/fphys.2018.00466

\section{Biological Roles of Aberrantly Expressed Glycosphingolipids and Related Enzymes in Human Cancer Development and Progression}

\author{
Dinghao Zhuo', Xiang $L^{2} i^{2}$ and Feng Guan ${ }^{1 *}$ \\ 1 Key Laboratory of Carbohydrate Chemistry and Biotechnology, Ministry of Education, School of Biotechnology, Jiangnan \\ University, Wuxi, China, ${ }^{2}$ Key Laboratory of Resource Biology and Biotechnology in Western China, Ministry of China, \\ College of Life Science, Northwest University, Xi'an, China
}

Glycosphingolipids (GSLS), which consist of a hydrophobic ceramide backbone and a hydrophilic carbohydrate residue, are an important type of glycolipid expressed in surface membranes of all animal cells. GSLs play essential roles in maintenance of plasma membrane stability, in regulation of numerous cellular processes (including adhesion, proliferation, apoptosis, and recognition), and in modulation of signal transduction pathways. GSLs have traditionally been classified as ganglio-series, lactoseries, or globo-series on the basis of their diverse types of oligosaccharide chains. Structures and functions of specific GSLs are also determined by their oligosaccharide chains. Different cells and tissues show differential expression of GSLs, and changes in structures of GSL glycan moieties occur during development of numerous types of human cancer. Association of GSLs and/or related enzymes with initiation and progression of cancer has been documented in 100s of studies, and many such GSLs are useful markers or targets for cancer diagnosis or therapy. In this review, we summarize (i) recent studies on aberrant expression and distribution of GSLs in common human cancers (breast, lung, colorectal, melanoma, prostate, ovarian, leukemia, renal, bladder, gastric); (ii) biological functions of specific GSLs in these cancers.

Keywords: glycosphingolipids, cellular processes, signaling pathway, aberrant expression, cancer development

\section{INTRODUCTION}

Glycosphingolipids (GSLs) are a subtype of glycolipids found in all animal cell surface membranes. GSLs have three basic components: sphingosine, fatty acid, and a carbohydrate residue (Hakomori, 2002). Major structural and functional classifications of GSLs have traditionally been based on glycans. GSLs can be subclassified as neutral, sialylated, or basic, or as ganglio-series, lacto-series, or globo-series (Hakomori, 2003). Some common types of GSLs (mainly ganglio-series) and related enzymes are shown in Figure 1. Two important functions of GSLs are mediation of cell-cell interactions and modulation of signal transduction pathways. Many studies have focused on the role of certain GSLs as cancer biomarkers and their application in cancer immunotherapy. Differential expression profiles of GSLs associated with oncogenic transformation were first reported almost 50 years ago (Hakomori and Murakami, 1968). A steadily increasing number of subsequent studies described aberrant expression and function of GSLs and related enzymes in 


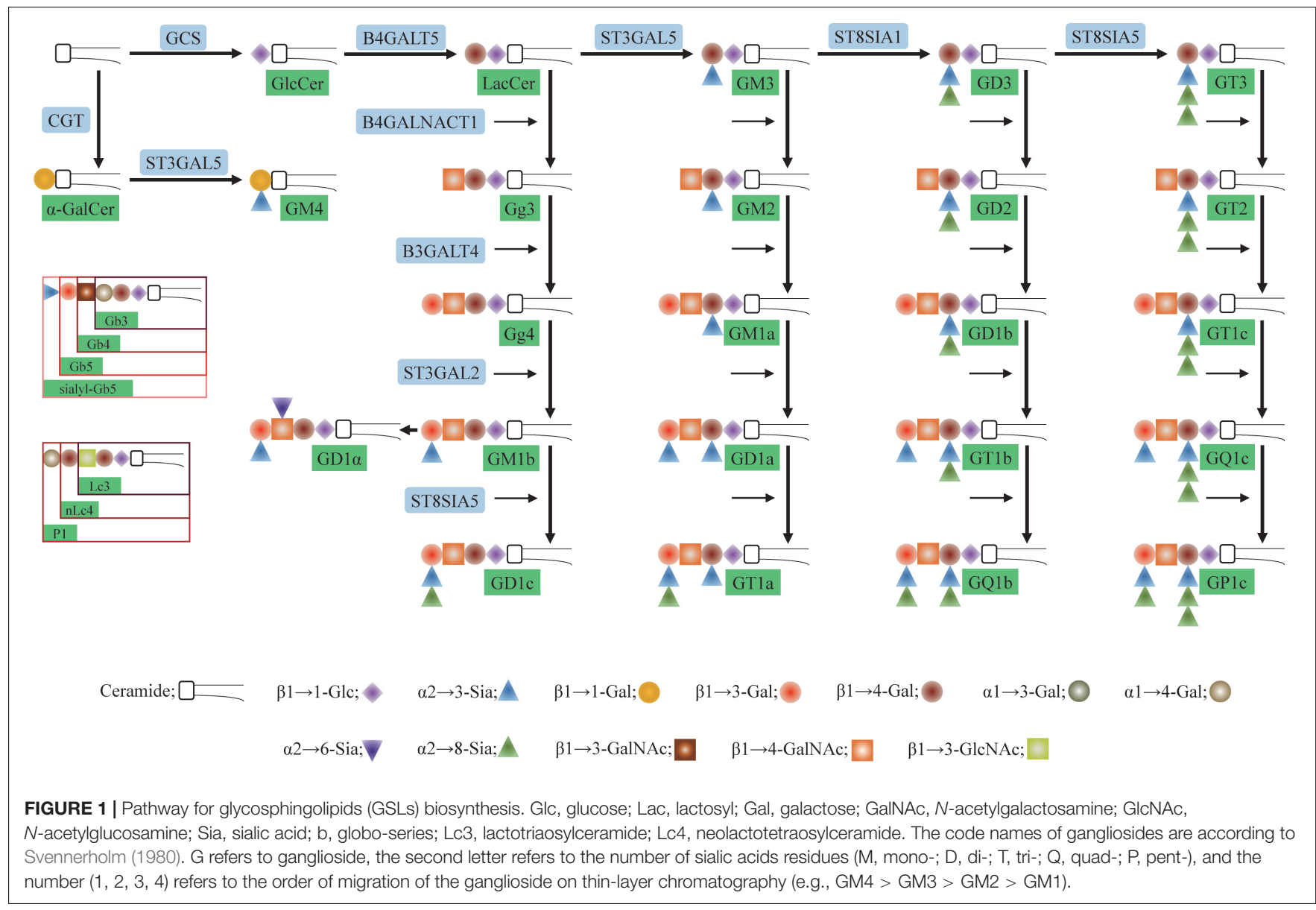

cancer cells and tissues. Here, we review recent studies along this line; these studies are summarized in Table $\mathbf{1 .}$

\section{BREAST CANCER}

Breast cancer is the most common type of cancer in women (Siegel et al., 2017b). Expression of certain GSLs in breast cancer tissue are distinct from that in normal breast tissue. Gangliosides GD3, 9-O-acetyl-GD3, and 9-O-acetyl-GT3 are barely detectable in normal breast tissues, but were found to be overexpressed in $\sim 50 \%$ of invasive ductal carcinomas (Marquina et al., 1996). In breast phyllodes tumors, mammosphere formation capacity was 3.9-fold greater in $\mathrm{GD}^{+}$cells than in $\mathrm{GD}^{-}$cells, and the GD2 ${ }^{+}$subpopulation displayed more mesenchymal stem cell characteristics (Lin et al., 2014). GD3/GD2 synthase ST8SIA1 was overexpressed in estrogen receptor (ER)-negative breast cancer tumors (Ruckhaberle et al., 2009), resulting in accumulation of GD2 (Cazet et al., 2012). Such accumulation enhanced proliferation and tumorigenicity of MDA-MB-231 breast cancer cells through ganglioside-mediated activation of c-Met receptor (Cazet et al., 2010, 2012; Sarkar et al., 2015). GD2 was identified as a specific cell surface marker of CD $44^{\text {hi }} / \mathrm{CD} 24^{\text {lo }}$ breast cancer stem cells (CSCs) (Battula et al., 2012). GD2 and GD3 levels were dramatically higher in breast CSCs than in non-CSCs, and knockdown of their synthases B4GALNT1 and ST8SIA1 resulted in phenotypic change from CSC to non-CSC (Liang et al., 2013). Follow-up studies demonstrated that ST8SIA1 maintains stem cell phenotype in breast CSCs, and that GD3 synthases may be involved in gefitinib-resistance of epidermal growth factor receptor (EGFR)-positive breast cancer cells (Liang et al., 2017). Stage-specific embryonic antigen (SSEA)-3, also known as Gb5, is another potential marker of breast CSCs (Cheung et al., 2016).

GD2 can be further converted to disialoganglioside GD1b. Exogenous or endogenous expression of GD1b (but not GD2) in human breast cancer MCF-7 results in apoptosis (Ha et al., 2016). Overexpression of GD1 $\alpha$ or its synthase ST6GALNAC5 in breast cancer cells promotes their metastasis to brain by enhancing adhesion to brain endothelial cells and reducing interactions with the blood-brain barrier (Bos et al., 2009; Vandermeersch et al., 2015; Drolez et al., 2016).

The epithelial-mesenchymal transition (EMT) phenomenon plays an important role in cancer metastasis. In normal murine mammary gland (NMuMG) cells, levels of Gg4 and its synthase B3GALT4 were significantly reduced during transforming growth factor- $\beta$ (TGF- $\beta$ )-induced EMT, and exogenous addition of Gg4 suppressed TGF- $\beta$-induced changes of morphology, motility, and levels of epithelial and mesenchymal markers (Guan et al., 2009). Gg4 appears to maintain epithelial cell membrane 
TABLE 1 | Glycosphingolipids and related enzymes aberrantly expressed in various types of cancer.

\begin{tabular}{|c|c|c|}
\hline Cancer & Upregulation or promotion & Downregulation or inhibition \\
\hline Breast & $\begin{array}{l}\text { GD2 and/or GD3 (Cazet et al., 2010, 2012; Battula et al., 2012; Liang } \\
\text { et al., 2013; Lin et al., 2014; Sarkar et al., 2015) } \\
\text { ST8SIA1 (Ruckhaberle et al., 2009; Liang et al., 2017) } \\
\text { Gb5 (Cheung et al., 2016) } \\
\text { GD1 } \alpha \text { (Bos et al., 2009; Vandermeersch et al., 2015; Drolez et al., } \\
\text { 2016) }\end{array}$ & $\begin{array}{l}\text { GD1b (Ha et al., 2016) } \\
\text { Gg4 and B3GALT4 (Guan et al., 2009, 2010; Guo et al., 2015) }\end{array}$ \\
\hline Lung & $\begin{array}{l}\text { Gb3 (Tyler et al., 2015) } \\
\text { GM2 (Yamada et al., 2011) } \\
\text { NeuGcGM3 (Hayashi et al., 2013; Alfonso et al., 2014; Piperno et al., } \\
\text { 2015; Palomo et al., 2016) }\end{array}$ & $\begin{array}{l}\text { ж-GalCer (Hasegawa et al., 2014; Ando et al., 2015; Ito et al., 2015; } \\
\text { Yamashita et al., 2016) } \\
\text { GALC (Peng et al., 2015) }\end{array}$ \\
\hline Colorectal & $\begin{array}{l}\text { Gb3 (Distler et al., 2009) } \\
\text { Gb4 (Park et al., 2012) } \\
\text { GCS (Haynes et al., 2012) } \\
\text { NEU3 (Shiozaki et al., 2009; Yamaguchi et al., 2012; Mozzi et al., 2015; } \\
\text { Takahashi et al., 2015) }\end{array}$ & $\begin{array}{l}\text { GD1a and GM1 (Kwak et al., 2011) } \\
\text { «-GalCer (Yoshioka et al., 2012; Dong et al., 2016) } \\
\text { GM3 (Chung et al., 2014) }\end{array}$ \\
\hline Melanoma & $\begin{array}{l}\text { NeuGcGM3 (Tringali et al., 2014) } \\
\text { d-GM3 (Yan et al., 2013) } \\
\text { GD2 and GD3 (Furukawa et al., 2014; Dobrenkov et al., 2016; Gargett } \\
\text { et al., 2016; Kaneko et al., 2016; Makino et al., 2016) } \\
\text { B4GalT5 (Shirane et al., 2014) }\end{array}$ & 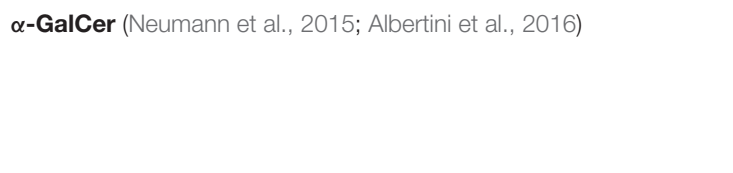 \\
\hline Leukemia & $\begin{array}{l}\text { NeuGcGM3 (Fernandez-Marrero et al., 2011; Casadesus et al., 2013) } \\
\text { GCS (Watters et al., 2013; Wang et al., 2014) } \\
\text { Lc3, GM3, and nLc4 (Wang et al., 2012) }\end{array}$ & $\begin{array}{l}\text { 从-GalCer (Weinkove et al., 2013) } \\
\text { GM3 (Jin et al., 2014; Delannoy et al., 2017) } \\
\text { GlcCer (Schwamb et al., 2012) }\end{array}$ \\
\hline Prostate & $\begin{array}{l}\text { GD1a and SPG (Hatano et al., 2011, 2012) } \\
\text { sialyl-Gb5 (Sivasubramaniyan et al., 2015; Hofner et al., 2016) } \\
\text { LacCer (Skotland et al., 2017) } \\
\text { Gg4 (Van Slambrouck et al., 2009, 2014) }\end{array}$ & DSGb5 (Shimada et al., 2014) \\
\hline Ovarian & $\begin{array}{l}\text { P1 (Jacob et al., 2014) } \\
\text { GD3 (Webb et al., 2012) }\end{array}$ & GM3 (Prinetti et al., 2011) \\
\hline Renal & $\begin{array}{l}\text { GM3 (Lin et al., 2012) } \\
\text { DSGb5 (Kawasaki et al., 2015) } \\
\text { LacCer (Chatterjee et al., 2013) }\end{array}$ & GlcCer (Chatterjee et al., 2013) \\
\hline Bladder & GCS (Sun et al., 2012) & GM3 (Wang et al., 2013) \\
\hline Gastric & Gb3 (Geyer et al., 2016) & \\
\hline
\end{tabular}

organization through its interaction with epithelial molecules such as E-cadherin and $\beta$-catenin (Guan et al., 2010). A TGF$\beta$ signal pathway-related complex formed by transcriptional factors Smad3 and Smad4 may directly bind to B3GALT4 promoter and reduce Gg4 expression during EMT (Guo et al., 2015).

\section{LUNG CANCER}

Lung cancer is a common cancer in both men and women, and the leading cause of cancer-related mortality (Jemal et al., 2011; Siegel et al., 2017b). Recent studies demonstrate the important roles of GSLs in lung cancer transformation and progression. $\alpha$-galactosylceramide ( $\alpha$-GalCer) (including allogeneic sources), a specific ligand of invariant natural killer $\mathrm{T}$ (iNKT) cells, exerts an anti-tumor effect by increasing production of the tumor growth suppressor IFN- $\gamma$ (Hasegawa et al., 2014). Several groups have attempted to enhance the therapeutic effects of $\alpha$-GalCer on lung cancer. Therapeutic efficiency of $\alpha$-GalCer was enhanced by inhibition of inducible nitric oxide synthase (iNOS) expression (Ito et al., 2015). Combination therapy with $\alpha$-GalCer and lipopolysaccharide obviously promoted tumor antigen-specific immune responses and suppressed tumor growth (Ando et al., 2015). Host CD40 apparently plays an essential role in the effectiveness of $\alpha$-GalCer treatment on lung metastasis (Yamashita et al., 2016).

Cisplatin is a chemotherapeutic agent widely used in treatment of many types of cancer. It induces cell apoptosis by increasing DNA fragmentation, inhibiting cell proliferation and activating mitochondria-dependent apoptotic pathway. Increased cell surface Gb3 expression led to acquisition of cisplatin resistance in non-small cell lung cancer (NSCLC) cells, and reduced glucosylceramide (GlcCer) synthase (GCS)-potentiated cisplatin cytotoxicity in NSCLC H1299 
cells. GCS-induced Gb3 expression has a regulatory role in acquisition of cisplatin resistance in NSCLC cells (Tyler et al., 2015). Expression of galactocerebrosidase (GALC), an enzyme that removes galactose from GSLs, is reduced in lung cancer and other human cancers. Downregulation of GALC gene resulted from hypermethylation of its promoter, suggesting that lung cancer tumorigenesis is due in part to epigenetic inactivation of GALC (Peng et al., 2015).

$\mathrm{N}$-acetylated ganglioside NeuAcGM3 is usually present in normal human tissues, whereas many human tumors express N-glycolylated ganglioside NeuGcGM3. NeuGcGM3 was present in 86 of 93 (93.5\%) NSCLC samples, as shown by immunohistochemical staining (Hayashi et al., 2013). NeuGcGM3, because of its selective expression in tumors, is a potentially useful target for immunotherapy, e.g., using Racotumomab-alum vaccine (Alfonso et al., 2014) or recombinant monoclonal antibody 14F7 (Piperno et al., 2015). In cases in which NeuGcGM3 and EGFR are involved jointly in tumor cell metastasis, therapeutic strategies that simultaneously target both molecules may be effective (Palomo et al., 2016).

Ganglioside GM2 is involved in cell adhesion and cell metastasis. GM2-expressing small cell lung cancer (SCLC) cells underwent multiple organ metastases in a SCID mouse model, and these metastases were inhibited by treatment with humanized anti-GM2 antibodies BIW-8962 and KM8927 (Yamada et al., 2011).

\section{COLORECTAL CANCER}

Another common cancer worldwide is colorectal cancer (Siegel et al., 2017a). Certain GSLs and related enzymes are aberrantly expressed in colorectal cancer. The glycosylation modification of GSLs during colorectal cancer progression were obtained in 13 colorectal tumor tissues, and these were found to be characterized by increased fucosylation, decreased acetylation and sulfation, reduced expression of globo-type glycans and disialyl gangliosides (Holst et al., 2013). In a study by Distler et al. (2009), 13 of $16(81.3 \%)$ colon cancer patients showed elevated expression of the GSL Gb3 (also known as CD77). As Gb3 is the receptor of Shiga toxin and binds to the STx B-subunit or its derivatives, which are therefore potential targets for colorectal cancer treatment. Gb4, synthesized from Gb3, has been characterized as an SSEA and is highly expressed in many types of cancer. In human colorectal carcinoma HCT116 cells, Gb4 enhanced activation of EGFRinduced MAPK/ERK signaling through direct interaction with EGFR (Park et al., 2012). Human colorectal carcinomaassociated GA733 antigen, also termed epithelial cell adhesion molecule (EpCAM), is selectively expressed in human colorectal carcinoma. Expression of gangliosides GD1a and GM1 greatly enhanced the anticancer effect of anti-EpCAM $m A b$ in human colon adenocarcinoma SW620 cells (Kwak et al., 2011).

A therapeutic effect on colorectal cancer has also been demonstrated for $\alpha$-GalCer. Treatment with $\alpha$-GalCer significantly reduced the number of colorectal tumors in AOM/DSS mice (Yoshioka et al., 2012). Combined treatment with $\alpha$-GalCer-loaded tumor cells and cytosine-phosphorothioate-guanine (a TLR9 agonist) in a mouse colorectal cancer model led to tumor growth inhibition and prolonged survival (Dong et al., 2016). In p53-deficient HCT116 cells, GCS level was reduced by treatment with mitomycin C, a DNA-damaging agent. Apoptosis was significantly enhanced by simultaneous GCS inhibition and mitomycin $\mathrm{C}$ treatment in p53-deficient cells, but not in p53-expressing cells (Haynes et al., 2012). Cisplatin is also used for chemotherapy of colorectal cancer. GM3-mediated oxidative apoptosis was shown to be related to cisplatin-induced apoptosis of HCT116 cells (Chung et al., 2014).

NEU3, a human plasma membrane-associated sialidase that specifically hydrolyzes sialic acids on gangliosides, is upregulated in colorectal cancer and plays an important role in malignancy (Shiozaki et al., 2009). In a mouse model of colitis-associated colon carcinogenesis induced by azoxymethane and dextran sodium sulfate, NEU3-deficient mice were less susceptible than wild-type mice (Yamaguchi et al., 2012). NEU3 therefore seems to be involved in inflammation-dependent tumor development. NEU3 also enhances EGFR activation through desialylation without affecting EGFR mRNA or protein expression (Mozzi et al., 2015). In HT-29 and HCT116 colorectal cancer cells, NEU3 silencing significantly reduced clonogenicity and downregulated stemness and Wnt-related genes, suggesting that Wnt signaling contributes to NEU3-induced tumorigenesis through maintenance of stem-like characteristics of these cells (Takahashi et al., 2015).

\section{MELANOMA}

Melanoma is the type of skin cancer with highest mortality rate, resulting annually in $\sim 60,000$ deaths in $\sim 3$ million patients worldwide (Wang et al., 2016). Certain GSLs were found to be specifically expressed and serve as distinctive molecular markers in melanoma cells (Hakomori, 2001). Among patients with various types of melanoma, survival was lowest for those having high levels of GM3 (mainly NeuGcGM3) in isolated melanoma cells (“cluster 1"). Such cluster 1 cells displayed highest malignant properties in terms of growth in soft agar, in vitro invasiveness, and expression of anti-apoptotic proteins (Tringali et al., 2014). The deacetylated GM3 (d-GM3) variant was found in metastatic melanomas but not in non-invasive melanomas or benign nevi. d-GM3 apparently promoted metastasis of human melanoma cells via the uPAR/integrin and p38 MAPK pathways (Yan et al., 2013).

GD2 and GD3 are highly and specifically expressed in most human melanoma tissues, and their expression is correlated with malignant properties such as cell proliferation and invasiveness (Dobrenkov et al., 2016). Molecules involved in GD3-mediated signaling pathways, such as p130Cas and paxillin, are potential targets for melanoma treatment. RNAi blocking of p130Cas and/or paxillin strongly suppressed melanoma growth (Makino et al., 2016). Stimulation by hepatocyte growth factor (HGF) or adhesion to collagen type I enhanced cell 
proliferation and apoptosis resistance via MAPK and Akt signaling pathways in GD3+, but not GD3-, human melanoma $\mathrm{N} 1$ cells. Increased GD3 expression promoted melanoma cell adhesion to surrounding tissues and susceptibility to HGF present in the tumor microenvironment, leading to synergy of multiple extracellular signals in melanoma tissue (Furukawa et al., 2014). Kaneko et al. (2016) showed that enhancement of melanoma malignant properties by GD3 may result in part from recruitment of $\gamma$-secretase to rafts, facilitating efficient cleavage of neogenin. GD2-specific chimeric antigen receptor (CAR) T-cells provide another promising new approach for melanoma cancer immunotherapy. These T-cells had a strong, rapid effect on metastatic melanoma, and blocking of PD-1 promoted CAR T-cell survival and killing of PD-L1 ${ }^{+}$tumor cells (Gargett et al., 2016).

The lactosylceramide (LacCer) synthase B4GalT5 was upregulated during malignant transformation of mouse melanoma B16-F10 cells, and reduced expression of the B4GalT5 gene significantly reduced tumorigenic and metastatic potential (Shirane et al., 2014). $\alpha$-GalCer exerted anti-tumor effects through eff activation of iNKT cells in melanoma as in some other types of cancer (Neumann et al., 2015; Albertini et al., 2016).

\section{LEUKEMIA}

Leukemia is a group of cancers that usually begin in the bone marrow and lead to high numbers of abnormal white blood cells. $\sim 90 \%$ of leukemias occur in adults, in whom the most common types are acute myeloid leukemia (AML) and chronic lymphocytic leukemia (CLL). It is also the most common cancer in children, in whom $\sim 75 \%$ of cases are acute lymphoblastic leukemia (ALL). Differentiation induction therapy of leukemia has received considerable research attention. Human chronic myelogenous leukemia (CML) K562 cells induced by caffeic acid phenethyl ester (CAPE) to differentiate toward megakaryocytic lineage showed increased GM3 synthase transcriptional activity and GM3 levels (Jin et al., 2014). GM3 expression was upregulated during differentiation of human acute monocytic leukemia THP-1 cells into macrophages (Delannoy et al., 2017). However, according to Wang et al. (2012), the study found that the levels of lactotriaosylceramide (Lc3), GM3 and neolactotetraosylceramide (nLc4) are higher in AML patients bone marrow than in healthy controls, especially the M1 subtype of AML. These results may indicate that the expression of GM3 is closely related to the various leukemia subtypes. Human normal tissues lack NeuGcGM3 because of a deletion in the cmah gene that encodes the enzyme responsible for NeuGc synthesis. Silencing of cmah in NeuGcGM3-expressing L1210 mouse lymphocytic leukemia B cells suppressed the cytotoxic effect by antibody 14F7 (Fernandez-Marrero et al., 2011). In a follow-up study, these cmah-silenced L1210 cells displayed enhanced NeuAcGM3 expression and an inhibitory effect on anchorage-independent cell growth and tumor development in vivo (Casadesus et al., 2013).
In patients with early-stage CLL, iNKT cells and the CD1d axis were fundamentally intact, and treatment with $\alpha$-GalCer was feasible and effective (Weinkove et al., 2013). Growth and survival of CLL cells were promoted by stimulation with B-cell receptor (BCR), CD40 ligand (CD40L), or interleukin4 (IL-4), through regulation of apoptosis resistance. Schwamb et al. (2012) found that anti-apoptotic effect of GlcCer was significantly enhanced by BCR stimulation in primary CLL cells.

Combination treatment of leukemic NK cells with C6-ceramide nanoliposomes and PPMP (a GCS inhibitor) induced apoptosis through the intrinsic mitochondrial cell death pathway (Watters et al., 2013). In K562/A02, a multidrug-resistant variant of CML K562 cells with GCS and Bcl-2 co-overexpression, apoptosis was enhanced by adriamycin (a chemotherapeutic agent used for treatment of various cancers) through downregulation of Bcl-2 via the ERK pathway. GCS inhibition also suppressed Bcl-2 in these cells. Thus, GCS may promote apoptosis resistance via upregulation of $\mathrm{Bcl}-2$ expression (Wang et al., 2014).

\section{PROSTATE AND OVARIAN CANCER}

Prostate cancer is the second most common type of cancer in men (Ferlay et al., 2015). GD1a and sialylparagloboside (SPG) showed higher expression in castration-resistant prostate cancer PC3 and DU145 cells than in hormone-sensitive prostate cancer cells or normal prostate epithelium. Such expression was indirectly controlled by NF- $\kappa$ B (mainly RelB) through transcriptional regulation of GD1a and SPG synthases ST3Gal2 and ST3Gal6 (Hatano et al., 2011). ST3Gal2 expression was regulated by androgen-dependent demethylation of $\mathrm{CpG}$ sites in its promoter (Hatano et al., 2012).

SSEA-4 (also known as sialyl-Gb5) plays an important role in prostate cancer development by affecting adhesion of cells to extracellular matrix (Sivasubramaniyan et al., 2015) and facilitating precise recognition of basal epithelial stem cell/progenitor cell lineages (Hofner et al., 2016). Disialosyl globopentaosylceramide (DSGb5) is expressed in benign prostate tissue but not in prostate cancer. However, cancer cells of patients with a worse prognosis show high expression levels of DSGb5, this alteration may indicate the progression of malignant potential of prostate cancer. Therefore, DSGb5 has a potential as a novel prostate cancer marker (Shimada et al., 2014).

Levels of LacCer (d18:1/16:0) in urinary exosomes were 95\% higher in prostate cancer patients than in healthy controls (Skotland et al., 2017). The carbohydrate moiety of Gg4 interacts with $\alpha 2,3$-linked sialic acid residues of integrin $\alpha 2 \beta 1$, and adhesion, migration, and invasiveness of prostate cancer $\mathrm{C} 4-2 \mathrm{~B}$ cells are affected by colocalization of these molecules (Van Slambrouck et al., 2009, 2014).

Ovarian cancer is the seventh most common cancer and eighth most common cause of cancer-related death in women. Rajanayake et al. (2016) compared GSL profiles in epithelial ovarian cancer SKOV3 cells vs. benign ovarian T29 cells. Five 
neutral GSLs were found only in SKOV3 cells, and several sialylated GSLs were differentially expressed. Gangliosides are concentrated primarily in lipid rafts - particularly caveolae, a type of lipid raft enriched in caveolins and functioning in signal transduction. Recombinant human ovarian cancer A2780 cells overexpressing GM3 synthase displayed reduced motility due to inactivation of $\mathrm{c}$-Src by ganglioside/caveolin-1 complex (Prinetti et al., 2011). The neolacto-series GSL P1 was found to be expressed on both erythrocytes and ovarian cancer cells, and appears to be a novel tumor-associated antigen associated with cell migration (Jacob et al., 2014). Webb et al. (2012) showed that GD3 in ovarian cancer ascites fluid is involved in a mechanism of early tumor immune evasion, based on its high affinity for CD1d and consequent blocking of innate immune activation of NKT cells.

\section{RENAL, BLADDER, AND GASTRIC CANCERS}

Bladder, renal, and gastric cancers are also fairly common in humans. These types of cancer also display abnormal expression of certain GSLs and related enzymes.

Following implantation of renal cancer cells into BALB/c mice, increased tumor volume was accompanied by upregulation of LacCer. Tumor volume was strongly reduced by treatment with D-PDMP, an inhibitor of GCS and LacCer synthase. D-PDMP treatment led to increased GlcCer level, possibly because of reduced activity of GlcCer glucosidase (Chatterjee et al., 2013). Confusingly, in some cases a particular GSL may display opposite effects in different cancer types (see Table 1). For example, GM3 acts as negative regulator of most cancers, the expression of GM3 (d18:1/22:1) in renal cancer patients were higher than in healthy controls (Lin et al., 2012). Similarly, high DSGb5 expression levels exhibit greater migration potential in renal cell carcinoma cells (Kawasaki et al., 2015), but the expression of DSGb5 is decreased in the early stage of transformation of prostate cancer from benign glands. These results may suggest that certain GSLs play a very complex role during the development and progression of renal cancer.

GCS is highly expressed in bladder cancer, and correlated with poor prognosis (Sun et al., 2012). In human bladder cancer YTS-1, T24, 5637, and KK47 cells, exogenous addition of GM3 reduced cell proliferation, cell adhesion, and EGFR phosphorylation (Wang et al., 2013).

Geyer et al. (2016) identified Gb3 in gastric carcinoma patients and cell lines using recombinant variant STxB-Cy3. Immunofluorescence analysis revealed expression of $\mathrm{Gb} 3$ in the majority of patients $(36 / 50 ; 72 \%)$ and cell lines $(6 / 10 ; 60 \%)$.

\section{SUMMARY AND PERSPECTIVES}

Glycosphingolipids play an essential role in maintaining normal physiological functions of cells. In many types of human cancer, aberrant expression of specific GSLs and related enzymes is strongly associated with tumor initiation and malignant transformation. Cancer immunotherapy is a highly promising approach that use of the immune system to treat cancer (Couzin-Frankel, 2013). In view of the aberrant expression of specific GSLs in many cancer, certain GSLs are selected as tumor-associated antigens and their antibodies are currently under preclinical studies or clinical investigation, also including molecular vaccines. For example, the antibody hu14.18K322A, which specifically recognize GD2, is being investigated in a phase II trial in neuroblastoma patients (Furman et al., 2017). Another example, the antibody BIW-8962, targets GM2, which is highly expressed in lung cancer (Lee et al., 2017). Racotumomab as an anti-idiotypic antibody vaccine that response against NeuGcGM3 can significantly extend the life of lung cancer patients by inhibiting the growth of their tumors. After a successful phase II/III study, Racotumomab adjuvanted with aluminum hydroxide was conditionally approved in Latin American countries as maintenance therapy for NSCLC (Gabri et al., 2016). Research shows NeuGcGM3 was highly expressed in many different human cancers, heralding a huge potential of Racotumomab or other NeuGcGM3-based vaccines for cancer immunotherapy. The Globo-series are another attractive targets. The antibodies against Gb3, Gb4, and Globo $\mathrm{H}$ have been shown to be effective as anti-tumor agents. In addition, their relevant vaccines are equally valid approach for cancer immunotherapy (Danishefsky et al., 2015). Meanwhile, certain GSLs can be used as tumor inhibitor. One example, $\alpha$-GalCer exhibits a strong anti-tumor effect and new therapeutic method are undergoing clinical trials (Gasser et al., 2018). With the deepening and development of research, we believe more GSLs will be found to have tremendous applicable value on cancer therapy.

The relationships between expression of many GSL species and development of various types of cancer remain unclear. The molecular mechanisms underlying the effects of GSLs on cancer development and progression also need to be elucidated. There are more than 400 species of GSLs in mammals (Hakomori, 2003). Determine the expression of these various GSLs and understanding the functional significance of this diversity in cancer is thus a challenging task. In recent years, mass spectrometry and its correlative technology has been widely explored for the identification and quantification of GSLs due to its high resolution, sensitivity, and accuracy. But owing to the complexity of GSLs, acquisition and accurate analysis of the category of glycosidic bond and the specific oligosaccharide structures, for instance, isomers with different glycan chains such as GM1a and GM1b, same glycan chain but different ceramide portions, is still in a difficult situation (Sarbu et al., 2016). Speaking of that, the emerging need for developing the effective technology to analyze the GSL is thus requested.

Great progress has been made during the past two decades in use of certain GSLs as targets for cancer immunotherapy and diagnosis. The foreseeable progress of the glycobiology field, with the rapid expansion of new ideas and new methods, especially the improvement of mass spectrometry technology, which are 
providing increasing advances in the understanding of how GSLs impact cancer progression, will allow the development of a relatively unexploited field of cancer treatments based on aberrant expression of GSLs, leading to exciting and novel clinical applications.

\section{AUTHOR CONTRIBUTIONS}

FG conceived and designed the article frame. DZ, XL, and FG wrote the paper.

\section{REFERENCES}

Albertini, M. R., Ranheim, E. A., Zuleger, C. L., Sondel, P. M., Hank, J. A., Bridges, A., et al. (2016). Phase I study to evaluate toxicity and feasibility of intratumoral injection of $\alpha$-gal glycolipids in patients with advanced melanoma. Cancer Immunol. Immunother. 65, 897-907. doi: 10.1007/s00262-0161846-1

Alfonso, S., Valdes-Zayas, A., Santiesteban, E. R., Flores, Y. I., Areces, F., Hernandez, M., et al. (2014). A randomized, multicenter, placebo-controlled clinical trial of racotumomab-alum vaccine as switch maintenance therapy in advanced non-small cell lung cancer patients. Clin. Cancer Res. 20, 3660-3671. doi: 10.1158/1078-0432.CCR-13-1674

Ando, T., Ito, H., Arioka, Y., Ogiso, H., and Seishima, M. (2015). Combination therapy with $\alpha$-galactosylceramide and a Toll-like receptor agonist exerts an augmented suppressive effect on lung tumor metastasis in a mouse model. Oncol. Rep. 33, 826-832. doi: 10.3892/or.2014.3634

Battula, V. L., Shi, Y., Evans, K. W., Wang, R. Y., Spaeth, E. L., Jacamo, R. O., et al. (2012). Ganglioside GD2 identifies breast cancer stem cells and promotes tumorigenesis. J. Clin. Invest. 122, 2066-2078. doi: 10.1172/JCI59735

Bos, P. D., Zhang, X. H., Nadal, C., Shu, W., Gomis, R. R., Nguyen, D. X., et al. (2009). Genes that mediate breast cancer metastasis to the brain. Nature 459, 1005-1009. doi: $10.1038 /$ nature 08021

Casadesus, A. V., Fernandez-Marrero, Y., Clavell, M., Gomez, J. A., Hernandez, T., Moreno, E., et al. (2013). A shift from N-glycolyl- to $\mathrm{N}$-acetyl-sialic acid in the GM3 ganglioside impairs tumor development in mouse lymphocytic leukemia cells. Glycoconj. J. 30, 687-699. doi: 10.1007/s10719-013-9473-y

Cazet, A., Bobowski, M., Rombouts, Y., Lefebvre, J., Steenackers, A., Popa, I., et al. (2012). The ganglioside G(D2) induces the constitutive activation of c-Met in MDA-MB-231 breast cancer cells expressing the G(D3) synthase. Glycobiology 22, 806-816. doi: 10.1093/glycob/cws049

Cazet, A., Lefebvre, J., Adriaenssens, E., Julien, S., Bobowski, M., Grigoriadis, A., et al. (2010). GD(3) synthase expression enhances proliferation and tumor growth of MDA-MB-231 breast cancer cells through c-Met activation. Mol. Cancer Res. 8, 1526-1535. doi: 10.1158/1541-7786.MCR-10-0302

Chatterjee, S., Alsaeedi, N., Hou, J., Bandaru, V. V., Wu, L., Halushka, M. K., et al. (2013). Use of a glycolipid inhibitor to ameliorate renal cancer in a mouse model. PLoS One 8:e63726. doi: 10.1371/journal.pone.0063726

Cheung, S. K., Chuang, P. K., Huang, H. W., Hwang-Verslues, W. W., Cho, C. H., Yang, W. B., et al. (2016). Stage-specific embryonic antigen-3 (SSEA-3) and $\beta 3$ GalT5 are cancer specific and significant markers for breast cancer stem cells. Proc. Natl. Acad. Sci. U.S.A. 113, 960-965. doi: 10.1073/pnas.152260 2113

Chung, T. W., Choi, H. J., Kim, S. J., Kwak, C. H., Song, K. H., Jin, U. H., et al. (2014). The ganglioside GM3 is associated with cisplatin-induced apoptosis in human colon cancer cells. PLoS One 9:e92786. doi: 10.1371/journal.pone. 0092786

Couzin-Frankel, J. (2013). Breakthrough of the year 2013. Cancer immunotherapy. Science 342, 1432-1433. doi: 10.1126/science.342.6165.1432

Danishefsky, S. J., Shue, Y. K., Chang, M. N., and Wong, C. H. (2015). Development of Globo-H cancer vaccine. Acc. Chem. Res. 48, 643-652. doi: 10.1021/ ar5004187

Delannoy, C. P., Rombouts, Y., Groux-Degroote, S., Holst, S., Coddeville, B., Harduin-Lepers, A., et al. (2017). Glycosylation changes triggered by the

\section{FUNDING}

This work was supported by the National Natural Science Foundation of China (Grant Nos. 81672537 and 81470294), and the Hundred-Talent Program of Shaanxi Province.

\section{ACKNOWLEDGMENTS}

The authors are grateful to Dr. S. Anderson for English editing of the manuscript.

differentiation of monocytic THP-1 cell line into macrophages. J. Proteome Res. 16, 156-169. doi: 10.1021/acs.jproteome.6b00161

Distler, U., Souady, J., Hulsewig, M., Drmic-Hofman, I., Haier, J., Friedrich, A. W., et al. (2009). Shiga toxin receptor Gb3Cer/CD77: tumor-association and promising therapeutic target in pancreas and colon cancer. PLoS One 4:e6813. doi: 10.1371 /journal.pone. 0006813

Dobrenkov, K., Ostrovnaya, I., Gu, J., Cheung, I. Y., and Cheung, N. K. (2016). Oncotargets GD2 and GD3 are highly expressed in sarcomas of children, adolescents, and young adults. Pediatr. Blood Cancer 63, 1780-1785. doi: 10.1002/pbc.26097

Dong, T., Yi, T., Yang, M., Lin, S., Li, W., Xu, X., et al. (2016). Co-operation of $\alpha$-galactosylceramide-loaded tumour cells and TLR9 agonists induce potent anti-tumour responses in a murine colon cancer model. Biochem. J. 473, 7-19. doi: 10.1042/BJ20150129

Drolez, A., Vandenhaute, E., Delannoy, C. P., Dewald, J. H., Gosselet, F., Cecchelli, R., et al. (2016). ST6GALNAC5 expression decreases the interactions between breast cancer cells and the human blood-brain barrier. Int. J. Mol. Sci. 17:E1309. doi: 10.3390/ijms17081309

Ferlay, J., Soerjomataram, I., Dikshit, R., Eser, S., Mathers, C., Rebelo, M., et al. (2015). Cancer incidence and mortality worldwide: sources, methods and major patterns in GLOBOCAN 2012. Int. J. Cancer 136, E359-E386. doi: 10.1002/ijc. 29210

Fernandez-Marrero, Y., Hernandez, T., Roque-Navarro, L., Talavera, A., Moreno, E., Grinan, T., et al. (2011). Switching on cytotoxicity by a single mutation at the heavy chain variable region of an anti-ganglioside antibody. Mol. Immunol. 48, 1059-1067. doi: 10.1016/j.molimm.2011.01.008

Furman, W. L., Shulkin, B. L., Federico, S. M., McCarville, M. B., Davidoff, A. M., Krasin, M. J., et al. (2017). Early response rates and Curie scores at end of induction: an update from a phase II study of an anti-GD2 monoclonal antibody (mAb) with chemotherapy (CT) in newly diagnosed patients (pts) with high-risk (HR) neuroblastoma (NB). J. Clin. Oncol. 35, 10534-10534.

Furukawa, K., Kambe, M., Miyata, M., Ohkawa, Y., Tajima, O., and Furukawa, K. (2014). Ganglioside GD3 induces convergence and synergism of adhesion and hepatocyte growth factor/Met signals in melanomas. Cancer Sci. 105, 52-63. doi: $10.1111 /$ cas. 12310

Gabri, M. R., Cacciavillano, W., Chantada, G. L., and Alonso, D. F. (2016). Racotumomab for treating lung cancer and pediatric refractory malignancies. Expert Opin. Biol. Ther. 16, 573-578. doi: 10.1517/14712598.2016.1157579

Gargett, T., Yu, W., Dotti, G., Yvon, E. S., Christo, S. N., Hayball, J. D., et al. (2016). GD2-specific CAR T cells undergo potent activation and deletion following antigen encounter but can be protected from activation-induced cell death by PD-1 Blockade. Mol. Ther. 24, 1135-1149. doi: 10.1038/mt.2016.63

Gasser, O., Sharples, K. J., Barrow, C., Williams, G. M., Bauer, E., Wood, C. E., et al. (2018). A phase I vaccination study with dendritic cells loaded with NY-ESO-1 and $\alpha$-galactosylceramide: induction of polyfunctional $\mathrm{T}$ cells in high-risk melanoma patients. Cancer Immunol. Immunother. 67, 285-298. doi: 10.1007/s00262-017-2085-9

Geyer, P. E., Maak, M., Nitsche, U., Perl, M., Novotny, A., Slotta-Huspenina, J., et al. (2016). Gastric adenocarcinomas express the glycosphingolipid Gb3/CD77: targeting of gastric cancer cells with shiga toxin B-subunit. Mol. Cancer Ther. 15, 1008-1017. doi: 10.1158/1535-7163.MCT-15-0633

Guan, F., Handa, K., and Hakomori, S. I. (2009). Specific glycosphingolipids mediate epithelial-to-mesenchymal transition of human and mouse epithelial 
cell lines. Proc. Natl. Acad. Sci. U.S.A. 106, 7461-7466. doi: 10.1073/pnas. 0902368106

Guan, F., Schaffer, L., Handa, K., and Hakomori, S. I. (2010). Functional role of gangliotetraosylceramide in epithelial-to-mesenchymal transition process induced by hypoxia and by TGF-\{beta\}. FASEB J. 24, 4889-4903. doi: 10.1096/ fj.10-162107

Guo, J., Song, B., Li, X., Hع, C., Yang, G., Yang, X., et al. (2015). Downregulation of gangliotetraosylceramide and $\beta 1$, 3-galactosyltransferase- 4 gene expression by Smads during transforming growth factor $\beta$-induced epithelial-mesenchymal transition. Mol. Med. Rep. 11, 2241-2247. doi: 10.3892/mmr.2014.2912

Ha, S. H., Lee, J. M., Kwon, K. M., Kwak, C. H., Abekura, F., Park, J. Y., et al. (2016). Exogenous and endogeneous disialosyl ganglioside GD1b induces apoptosis of MCF-7 human breast cancer cells. Int. J. Mol. Sci. 17:E652. doi: 10.3390/ ijms17050652

Hakomori, S. (2001). Tumor-associated carbohydrate antigens defining tumor malignancy: basis for development of anti-cancer vaccines. Adv. Exp. Med. Biol. 491, 369-402.

Hakomori, S. (2003). Structure, organization, and function of glycosphingolipids in membrane. Curr. Opin. Hematol. 10, 16-24.

Hakomori, S.-i. (2002). The glycosynapse. Proc. Natl. Acad. Sci. U.S.A. 99, 225-232. doi: $10.1073 /$ pnas. 012540899

Hakomori, S. I., and Murakami, W. T. (1968). Glycolipids of hamster fibroblasts and derived malignant-transformed cell lines. Proc. Natl. Acad. Sci. U.S.A. 59, 254-261.

Hasegawa, H., Yamashita, K., Otubo, D., Fujii, S., Kamigaki, T., Kuroda, D., et al. (2014). Allogeneic DCG promote lung NK cell activation and antitumor effect after invariant NKT cell activation. Anticancer Res. 34, 3411-3417.

Hatano, K., Miyamoto, Y., Mori, M., Nimura, K., Nakai, Y., Nonomura, N., et al. (2012). Androgen-regulated transcriptional control of sialyltransferases in prostate cancer cells. PLoS One 7:e31234. doi: 10.1371/journal.pone.003 1234

Hatano, K., Miyamoto, Y., Nonomura, N., and Kaneda, Y. (2011). Expression of gangliosides, GDla, and sialyl paragloboside is regulated by NF-кBdependent transcriptional control of $\alpha 2,3$-sialyltransferase I, II, and VI in human castration-resistant prostate cancer cells. Int. J. Cancer 129, 1838-1847. doi: $10.1002 /$ ijc. 25860

Hayashi, N., Chiba, H., Kuronuma, K., Go, S., Hasegawa, Y., Takahashi, M., et al. (2013). Detection of N-glycolyated gangliosides in non-small-cell lung cancer using GMR8 monoclonal antibody. Cancer Sci. 104, 43-47. doi: 10.1111/cas. 12027

Haynes, T. A., Filippov, V., Filippova, M., Yang, J., Zhang, K., and DuerksenHughes, P. J. (2012). DNA damage induces down-regulation of UDPglucose ceramide glucosyltransferase, increases ceramide levels and triggers apoptosis in p53-deficient cancer cells. Biochim. Biophys. Acta 1821, 943-953. doi: 10.1016/j.bbalip.2012.02.002

Hofner, T., Klein, C., Eisen, C., Rigo-Watermeier, T., Haferkamp, A., and Sprick, M. R. (2016). Protein profile of basal prostate epithelial progenitor cells-stage-specific embryonal antigen 4 expressing cells have enhanced regenerative potential in vivo. J. Cell Mol. Med. 20, 721-730. doi: 10.1111/jcmm. 12785

Holst, S., Stavenhagen, K., Balog, C. I., Koeleman, C. A., McDonnell, L. M., Mayboroda, O. A., et al. (2013). Investigations on aberrant glycosylation of glycosphingolipids in colorectal cancer tissues using liquid chromatography and matrix-assisted laser desorption time-of-flight mass spectrometry (MALDI-TOF-MS). Mol. Cell. Proteomics 12, 3081-3093. doi: 10.1074/mcp.M113.030387

Ito, H., Ando, T., and Seishima, M. (2015). Inhibition of iNOS activity enhances the anti-tumor effects of $\alpha$-galactosylceramide in established murine cancer model. Oncotarget 6, 41863-41874. doi: 10.18632/oncotarget.6172

Jacob, F., Anugraham, M., Pochechueva, T., Tse, B. W., Alam, S., Guertler, R., et al. (2014). The glycosphingolipid $\mathrm{P}(1)$ is an ovarian cancer-associated carbohydrate antigen involved in migration. Br. J. Cancer 111, 1634-1645. doi: 10.1038/bjc.2014.455

Jemal, A., Bray, F., Center, M. M., Ferlay, J., Ward, E., and Forman, D. (2011). Global cancer statistics. CA Cancer J. Clin. 61, 69-90. doi: 10.3322/caac.20107

Jin, U. H., Chung, T. W., Song, K. H., Kwak, C. H., Choi, H. J., Ha, K. T., et al. (2014). Ganglioside GM3 is required for caffeic acid phenethyl ester-induced megakaryocytic differentiation of human chronic myelogenous leukemia K562 cells. Biochem. Cell Biol. 92, 243-249. doi: 10.1139/bcb-20140015

Kaneko, K., Ohkawa, Y., Hashimoto, N., Ohmi, Y., Kotani, N., Honke, K., et al. (2016). Neogenin, defined as a GD3-associated molecule by enzyme-mediated activation of radical sources, confers malignant properties via intracytoplasmic domain in melanoma cells. J. Biol. Chem. 291, 16630-16643. doi: 10.1074/jbc M115.708834

Kawasaki, Y., Ito, A., Kakoi, N., Shimada, S., Itoh, J., Mitsuzuka, K., et al. (2015). Ganglioside, disialosyl globopentaosylceramide (DSGb5), enhances the migration of renal cell carcinoma cells. Tohoku J. Exp. Med. 236, 1-7. doi: $10.1620 /$ tjem.236.1

Kwak, D. H., Ryu, J. S., Kim, C. H., Ko, K., Ma, J. Y., Hwang, K. A., et al. (2011). Relationship between ganglioside expression and anti-cancer effects of the monoclonal antibody against epithelial cell adhesion molecule in colon cancer. Exp. Mol. Med. 43, 693-701. doi: 10.3858/emm.2011.43. 12.080

Lee, J., Kim, J., Kim, S., Kang, J., Lee, D. H., Cho, B. C., et al. (2017). P1.01-070 BIW8962, an Anti-GM2 ganglioside monoclonal antibody, in advanced/recurrent lung cancer: a phase I/II study. J. Thorac. Oncol. 12, S1921-S1922. doi: 10.1016/ j.jtho.2017.09.724

Liang, Y.-J., Ding, Y., Levery, S. B., Lobaton, M., Handa, K., and Hakomori, S.-I. (2013). Differential expression profiles of glycosphingolipids in human breast cancer stem cells vs. cancer non-stem cells. Proc. Natl. Acad. Sci. 110 4968-4973. doi: 10.1073/pnas.1302825110

Liang, Y. J., Wang, C. Y., Wang, I. A., Chen, Y. W., Li, L. T., Lin, C. Y., et al. (2017). Interaction of glycosphingolipids GD3 and GD2 with growth factor receptors maintains breast cancer stem cell phenotype. Oncotarget 8, 47454-47473. doi: 10.18632/oncotarget.17665

Lin, J. J., Huang, C. S., Yu, J., Liao, G. S., Lien, H. C., Hung, J. T., et al. (2014). Malignant phyllodes tumors display mesenchymal stem cell features and aldehyde dehydrogenase/disialoganglioside identify their tumor stem cells. Breast Cancer Res. 16:R29. doi: 10.1186/bcr3631

Lin, L., Huang, Z., Gao, Y., Chen, Y., Hang, W., Xing, J., et al. (2012). LCMS-based serum metabolic profiling for genitourinary cancer classification and cancer type-specific biomarker discovery. Proteomics 12, 2238-2246. doi: $10.1002 /$ pmic. 201200016

Makino, Y., Hamamura, K., Takei, Y., Bhuiyan, R. H., Ohkawa, Y., Ohmi, Y., et al. (2016). A therapeutic trial of human melanomas with combined small interfering RNAs targeting adaptor molecules p130Cas and paxillin activated under expression of ganglioside GD3. Biochim. Biophys. Acta 1860, 1753-1763. doi: 10.1016/j.bbagen.2016.04.005

Marquina, G., Waki, H., Fernandez, L. E., Kon, K., Carr, A., Valiente, O., et al. (1996). Gangliosides expressed in human breast cancer. Cancer Res. 56, 5165-5171.

Mozzi, A., Forcella, M., Riva, A., Difrancesco, C., Molinari, F., Martin, V., et al. (2015). NEU3 activity enhances EGFR activation without affecting EGFR expression and acts on its sialylation levels. Glycobiology 25, 855-868. doi: 10.1093/glycob/cwv026

Neumann, S., Young, K., Compton, B., Anderson, R., Painter, G., and Hook, S. (2015). Synthetic TRP2 long-peptide and $\alpha$-galactosylceramide formulated into cationic liposomes elicit CD8+ T-cell responses and prevent tumour progression. Vaccine 33, 5838-5844. doi: 10.1016/j.vaccine.2015. 08.083

Palomo, A. G., Santana, R. B., Perez, X. E., Santana, D. B., Gabri, M. R., Monzon, K. L., et al. (2016). Frequent co-expression of EGFR and NeuGcGM3 ganglioside in cancer: it's potential therapeutic implications. Clin. Exp. Metastasis 33, 717-725. doi: 10.1007/s10585-016-9811-0

Park, S. Y., Kwak, C. Y., Shayman, J. A., and Kim, J. H. (2012). Globoside promotes activation of ERK by interaction with the epidermal growth factor receptor. Biochim. Biophys. Acta 1820, 1141-1148. doi: 10.1016/j.bbagen.2012. 04.008

Peng, J., Chen, B., Shen, Z., Deng, H., Liu, D., Xie, X., et al. (2015). DNA promoter hypermethylation contributes to down-regulation of galactocerebrosidase gene in lung and head and neck cancers. Int. J. Clin. Exp. Pathol. 8, 11042-11050.

Piperno, G. M., Lopez-Requena, A., Predonzani, A., Dorvignit, D., Labrada, M., Zentilin, L., et al. (2015). Recombinant AAV-mediated in vivo long-term expression and antitumour activity of an anti-ganglioside GM3(Neu5Gc) antibody. Gene Ther. 22, 960-967. doi: 10.1038/gt.2015.71 
Prinetti, A., Cao, T., Illuzzi, G., Prioni, S., Aureli, M., Gagliano, N., et al. (2011). A glycosphingolipid/caveolin-1 signaling complex inhibits motility of human ovarian carcinoma cells. J. Biol. Chem. 286, 40900-40910. doi: 10.1074/jbc. M111.286146

Rajanayake, K. K., Taylor, W. R., and Isailovic, D. (2016). The comparison of glycosphingolipids isolated from an epithelial ovarian cancer cell line and a nontumorigenic epithelial ovarian cell line using MALDI-MS and MALDIMS/MS. Carbohydr. Res. 431, 6-14. doi: 10.1016/j.carres.2016.05.006

Ruckhaberle, E., Karn, T., Rody, A., Hanker, L., Gatje, R., Metzler, D., et al. (2009). Gene expression of ceramide kinase, galactosyl ceramide synthase and ganglioside GD3 synthase is associated with prognosis in breast cancer. J. Cancer Res. Clin. Oncol. 135, 1005-1013. doi: 10.1007/s00432-008-0536-6

Sarbu, M., Robu, A. C., Ghiulai, R. M., Vukelic, Z., Clemmer, D. E., and Zamfir, A. D. (2016). Electrospray ionization ion mobility mass spectrometry of human brain gangliosides. Anal. Chem. 88, 5166-5178. doi: 10.1021/acs.analchem. $6 \mathrm{~b} 00155$

Sarkar, T. R., Battula, V. L., Werden, S. J., Vijay, G. V., Ramirez-Pena, E. Q., Taube, J. H., et al. (2015). GD3 synthase regulates epithelial-mesenchymal transition and metastasis in breast cancer. Oncogene 34, 2958-2967. doi: 10.1038/onc. 2014.245

Schwamb, J., Feldhaus, V., Baumann, M., Patz, M., Brodesser, S., Brinker, R., et al. (2012). B-cell receptor triggers drug sensitivity of primary CLL cells by controlling glucosylation of ceramides. Blood 120, 3978-3985. doi: 10.1182/ blood-2012-05-431783

Shimada, S., Ito, A., Kawasaki, Y., Kakoi, N., Taima, T., Mitsuzuka, K., et al. (2014). Ganglioside disialosyl globopentaosylceramide is an independent predictor of PSA recurrence-free survival following radical prostatectomy. Prostate Cancer Prostatic Dis. 17, 199-205. doi: 10.1038/pcan.2014.9

Shiozaki, K., Yamaguchi, K., Sato, I., and Miyagi, T. (2009). Plasma membraneassociated sialidase (NEU3) promotes formation of colonic aberrant crypt foci in azoxymethane-treated transgenic mice. Cancer Sci. 100, 588-594. doi: 10.1111/j.1349-7006.2008.01080.x

Shirane, K., Kuji, R., Tareyanagi, C., Sato, T., Kobayashi, Y., Furukawa, S., et al. (2014). Gene expression levels of $\beta 4$-galactosyltransferase 5 correlate with the tumorigenic potentials of B16-F10 mouse melanoma cells. Glycobiology 24, 532-541. doi: 10.1093/glycob/cwu021

Siegel, R. L., Miller, K. D., Fedewa, S. A., Ahnen, D. J., Meester, R. G. S., Barzi, A., et al. (2017a). Colorectal cancer statistics, 2017. CA Cancer J. Clin. 67, 177-193. doi: $10.3322 /$ caac. 21395

Siegel, R. L., Miller, K. D., and Jemal, A. (2017b). Cancer Statistics, 2017. CA Cancer J. Clin. 67, 7-30. doi: 10.3322/caac. 21387

Sivasubramaniyan, K., Harichandan, A., Schilbach, K., Mack, A. F., Bedke, J., Stenzl, A., et al. (2015). Expression of stage-specific embryonic antigen-4 (SSEA4) defines spontaneous loss of epithelial phenotype in human solid tumor cells. Glycobiology 25, 902-917. doi: 10.1093/glycob/cwv032

Skotland, T., Ekroos, K., Kauhanen, D., Simolin, H., Seierstad, T., Berge, V., et al. (2017). Molecular lipid species in urinary exosomes as potential prostate cancer biomarkers. Eur. J. Cancer 70, 122-132. doi: 10.1016/j.ejca.2016.10.011

Sun, C. C., Zhang, Z., Zhang, S. Y., Li, J., Li, Z. L., and Kong, C. Z. (2012). Upregulation of glucosylceramide synthase in urinary bladder neoplasms. Urol. Oncol. 30, 444-449. doi: 10.1016/j.urolonc.2010.04.012

Svennerholm, L. (1980). Ganglioside designation. Adv. Exp. Med. Biol. 125:11.

Takahashi, K., Hosono, M., Sato, I., Hata, K., Wada, T., Yamaguchi, K., et al. (2015). Sialidase NEU3 contributes neoplastic potential on colon cancer cells as a key modulator of gangliosides by regulating Wnt signaling. Int. J. Cancer 137, 1560-1573. doi: 10.1002/ijc.29527

Tringali, C., Silvestri, I., Testa, F., Baldassari, P., Anastasia, L., Mortarini, R., et al. (2014). Molecular subtyping of metastatic melanoma based on cell ganglioside metabolism profiles. BMC Cancer 14:560. doi: 10.1186/1471-2407-14-560

Tyler, A., Johansson, A., Karlsson, T., Gudey, S. K., Brannstrom, T., Grankvist, K., et al. (2015). Targeting glucosylceramide synthase induction of cell surface globotriaosylceramide (Gb3) in acquired cisplatin-resistance of lung cancer and malignant pleural mesothelioma cells. Exp. Cell Res. 336, 23-32. doi: 10.1016/j. yexcr.2015.05.012

Van Slambrouck, S., Groux-Degroote, S., Krzewinski-Recchi, M. A., Cazet, A., Delannoy, P., and Steelant, W. F. (2014). Carbohydrate-to-carbohydrate interactions between $\alpha 2,3$-linked sialic acids on $\alpha 2$ integrin subunits and asialoGM1 underlie the bone metastatic behaviour of LNCAP-derivative C4-2B prostate cancer cells. Biosci. Rep 34:e00138. doi: 10.1042/BSR20140096
Van Slambrouck, S., Hilkens, J., Bisoffi, M., and Steelant, W. F. (2009). AsialoGM1 and integrin $\alpha 2 \beta 1$ mediate prostate cancer progression. Int. J. Oncol. 35, 693-699.

Vandermeersch, S., Vanbeselaere, J., Delannoy, C. P., Drolez, A., Mysiorek, C., Guerardel, Y., et al. (2015). Accumulation of GD1 $\alpha$ Ganglioside in MDA-MB231 breast cancer cells expressing ST6GalNAc V. Molecules 20, 6913-6924. doi: 10.3390/molecules20046913

Wang, H., Isaji, T., Satoh, M., Li, D., Arai, Y., and Gu, J. (2013). Antitumor effects of exogenous ganglioside GM3 on bladder cancer in an orthotopic cancer model. Urology 81, 210.e11-5. doi: 10.1016/j.urology.2012.08.015

Wang, H., Naghavi, M., Allen, C., Barber, R., Bhutta, Z., Carter, A., et al. (2016). Global, regional, and national life expectancy, all-cause mortality, and causespecific mortality for 249 causes of death, 1980-2015: a systematic analysis for the Global Burden of Disease Study 2015. Lancet 388, 1459-1544. doi: 10.1016/ S0140-6736(16)31012-1

Wang, Q., Zou, J., Zhang, X., Mu, H., Yin, Y., and Xie, P. (2014). Glucosylceramide synthase promotes Bcl-2 expression via the ERK signaling pathway in the K562/A02 leukemia drug-resistant cell line. Int. J. Hematol. 100, 559-566. doi: 10.1007/s12185-014-1679-7

Wang, Z., Wen, L., Ma, X., Chen, Z., Yu, Y., Zhu, J., et al. (2012). High expression of lactotriaosylceramide, a differentiation-associated glycosphingolipid, in the bone marrow of acute myeloid leukemia patients. Glycobiology 22, 930-938. doi: 10.1093/glycob/cws061

Watters, R. J., Fox, T. E., Tan, S. F., Shanmugavelandy, S., Choby, J. E., Broeg, K., et al. (2013). Targeting glucosylceramide synthase synergizes with C6-ceramide nanoliposomes to induce apoptosis in natural killer cell leukemia. Leuk. Lymphoma 54, 1288-1296. doi: 10.3109/10428194.2012.752485

Webb, T. J., Li, X., Giuntoli, R. L. II, Lopez, P. H., Heuser, C., Schnaar, R. L., et al. (2012). Molecular identification of GD3 as a suppressor of the innate immune response in ovarian cancer. Cancer Res. 72, 3744-3752. doi: 10.1158/0008-5472. CAN-11-2695

Weinkove, R., Brooks, C. R., Carter, J. M., Hermans, I. F., and Ronchese, F. (2013). Functional invariant natural killer T-cell and CD1d axis in chronic lymphocytic leukemia: implications for immunotherapy. Haematologica 98, 376-384. doi: 10.3324/haematol.2012.072835

Yamada, T., Bando, H., Takeuchi, S., Kita, K., Li, Q., Wang, W., et al. (2011). Genetically engineered humanized anti-ganglioside GM2 antibody against multiple organ metastasis produced by GM2-expressing small-cell lung cancer cells. Cancer Sci. 102, 2157-2163. doi: 10.1111/j.1349-7006.2011. 02093.x

Yamaguchi, K., Shiozaki, K., Moriya, S., Koseki, K., Wada, T., Tateno, H., et al. (2012). Reduced susceptibility to colitis-associated colon carcinogenesis in mice lacking plasma membrane-associated sialidase. PLoS One 7:e41132. doi: 10. 1371/journal.pone.0041132

Yamashita, K., Hasegawa, H., Fujita, M., Nishi, M., Tanaka, T., Arimoto, A., et al. (2016). Host CD40 is essential for DCG treatment against metastatic lung cancer. Anticancer Res. 36, 3659-3665.

Yan, Q., Bach, D. Q., Gatla, N., Sun, P., Liu, J. W., Lu, J. Y., et al. (2013). Deacetylated GM3 promotes uPAR-associated membrane molecular complex to activate p38 MAPK in metastatic melanoma. Mol. Cancer Res. 11, 665-675. doi: 10.1158/1541-7786.MCR-12-0270-T

Yoshioka, K., Ueno, Y., Tanaka, S., Nagai, K., Onitake, T., Hanaoka, R., et al. (2012). Role of natural killer $\mathrm{T}$ cells in the mouse colitis-associated colon cancer model. Scand. J. Immunol. 75, 16-26. doi: 10.1111/j.1365-3083.2011. 02607.x

Conflict of Interest Statement: The authors declare that the research was conducted in the absence of any commercial or financial relationships that could be construed as a potential conflict of interest.

The handling Editor is currently co-organizing a Research Topic with one of the authors FG, and confirms the absence of any other collaboration.

Copyright (c) 2018 Zhuo, Li and Guan. This is an open-access article distributed under the terms of the Creative Commons Attribution License (CC BY). The use, distribution or reproduction in other forums is permitted, provided the original author(s) and the copyright owner are credited and that the original publication in this journal is cited, in accordance with accepted academic practice. No use, distribution or reproduction is permitted which does not comply with these terms. 